\title{
Can we accurately measure the ankle-brachial index in patients with atrial fibrillation?
}

\author{
Victor Aboyans ${ }^{1,2} \cdot$ lleana Desormais ${ }^{2,3}$
}

Received: 25 February 2018 / Revised: 2 March 2018 / Accepted: 4 March 2018 / Published online: 2 May 2018

(c) The Japanese Society of Hypertension 2018

Peripheral artery disease (PAD) is frequent in the elderly $[3,4]$. It can be easily detected by measurement of the ankle-brachial index (ABI), which is often proposed as the first-line diagnostic tool to detect this condition [5]. A cutoff of 0.90 is proposed to define PAD when the ABI is under this threshold [6].

Since atrial fibrillation (AF) is also increasingly prevalent with older age [5], the frequent coexistence of both conditions is expected. However, this association seems more than random, and several population studies have demonstrated an increased risk of incident AF, independent of age, in patients who have clinical or subclinical PAD detected by the ABI $[6,7]$. In turn, AF is associated with increased risk of incident PAD and its complications [8, 9].

Currently, the thromboembolic risk of AF is most often addressed using the CHADS2VASc score [10], where the presence of PAD contributes one point, increasing the odds for arterial thromboembolic events in patients with AF. Some authors have even proposed to measure the ABI in patients with AF to identify subclinical PAD, detected in $21 \%$ of patients hospitalized for AF by a systematic measurement of the ABI [11].

In this context, one important question is the reliability of the $\mathrm{ABI}$ measurement during $\mathrm{AF}$, with variable beat-to-beat heart rate and systolic pressure. In 2012, the AHA statements on the measurement, calculation and interpretation of the ABI did not address the issue of arrhythmia and its effect on the ABI results due to the lack of evidence at that

Victor Aboyans

victor.aboyans@unilim.fr

1 Department of Cardiology, Dupuytren University Hospital, Limoges, France

2 INSERM 1094, Tropical Neuroepidemiology, School of Medicine, Limoges University, Limoges, France

3 Department of Thoracic and Vascular Surgery and Medicine, Dupuytren University Hospital, Limoges, France moment [4]. The study performed by Dabrowski et al. [12], reported in this issue of the journal, sheds light on and brings an important piece of evidence for the reliability of the $\mathrm{ABI}$ measurement during $\mathrm{AF}$.

Indeed, the authors proposed a very elegant approach by comparing the $\mathrm{ABI}$ measured during $\mathrm{AF}$ and sinus rhythm (SR) on the same patients, taking the opportunity of planned electrical cardioversion to measure ABI before and after this intervention. The authors reported a lower ABI during AF than during SR but considered that the upper 95\% confidence interval margins for the median difference $(\sim 0.04)$ were not clinically significant and that the ABI could be considered accurate for the diagnosis of PAD during $\mathrm{AF}$ [12].

The prevalence of PAD $(\mathrm{ABI}<0.90)$ was low in this series $(0.3 \%)$ compared with what is usually reported, but this difference might be related to the relatively young age of these patients (mean age 66 years), which can be explained by the fact that most of these patients had recently had AF and been referred for cardioversion; therefore, older patients with permanent AF were excluded. Indeed, the data suggested more progressed atherosclerosis in patients with persistent/permanent AF [13]. However, it is noteworthy that five other patients had borderline ABI (0.90-0.99) on SR and would plausibly be classified as PAD if the ABI on AF was considered. However, one lesson from this study is that the prevalence of PAD in patients with AF may be overestimated when $\mathrm{ABI}$ is measured during $\mathrm{AF}$ rhythm, especially for those with an ABI close to the 0.90 threshold. Guidelines [4] suggest other tests when the ABI is borderline, which would not have consequences for the clinical management but is noteworthy in epidemiological/clinical studies where the prevalence of PAD in patients with $\mathrm{AF}$ is estimated using the ABI alone.

Upon further analysis, the authors found that heart rate may affect the reliability of the ABI measured during $\mathrm{AF}$ [12]. While the difference in ABI measured in SR was trivial in patients with heart rates below 100 , the $A B I$ values measured in those with faster heart rates were significantly 
different, reaching an average of more than 0.07 in the right leg. This finding highlights the fact that rather than arrhythmia, heart rate may significantly affect the ABI. Previous studies in SR demonstrated an inverse relationship between the ABI and heart rate in healthy individuals [14, 15]. In a study using cardiac pacing to change the heart rate, the brachial-to-central pressure ratio rose by 0.012 units for every $10 \mathrm{bpm}$, which can alter the ABI because of the greater distance of the ankles than the arms to the heart [15].

The study reported by Dabrowski et al. [12] in this issue provides important information regarding the measurement of ABI during AF: at an individual level, a normal ABI can accurately rule out $\mathrm{PAD}$ in a patient with $\mathrm{AF}$, while in borderline cases, the ABI may overdiagnose PAD, especially when the heart rate is above 100. In this case, and if the patient remains in AF, further diagnostic tests are necessary.

Of note, this study has been performed using the Doppler method, which is the reference method [4]. The conclusions drawn should not be extrapolated for other methods, especially the oscillometric method, which is expanding. Specific studies using the latter are mandated.

\section{Compliance with ethical standards}

Conflict of interest The authors declare that they have no conflict of interest.

\section{References}

1. Fowkes FG, Aboyans V, Fowkes FJ, McDermott MM, Sampson UK, Criqui MH. Peripheral artery disease: epidemiology and global perspectives. Nat Rev Cardiol. 2017;14:156-70.

2. Criqui MH, Aboyans V. Epidemiology of peripheral artery disease. Circ Res. 2015;116:1509-26.

3. Aboyans V, Ricco JB, Bartelink MEL, Björck M, Brodmann M, Cohnert T, Collet JP, Czerny M, De Carlo M, Debus S, EspinolaKlein C, Kahan T, Kownator S, Mazzolai L, Naylor AR, Roffi M, Röther J, Sprynger M, Tendera M, Tepe G, Venermo M, Vlachopoulos C, Desormais I. 2017 ESC Guidelines on the Diagnosis and Treatment of Peripheral Arterial Diseases, in collaboration with the European Society for Vascular Surgery (ESVS). Eur Heart J. 2017. https://doi.org/10.1093/eurheartj/ehx095.

4. Aboyans V, Criqui MH, Abraham P, Allison MA, Creager MA, Diehm C, Fowkes FG, Hiatt WR, Jönsson B, Lacroix P, Marin B, McDermott MM, Norgren L, Pande RL, Preux PM, Stoffers HE, Treat-Jacobson D, American Heart Association Council on Peripheral Vascular Disease; Council on Epidemiology and Prevention; Council on Clinical Cardiology; Council on Cardiovascular Nursing; Council on Cardiovascular Radiology and Intervention, and Council on Cardiovascular Surgery and Anesthesia. Measurement and interpretation of the ankle-brachial index: a scientific statement from the American Heart Association. Circulation. 2012;126:2890-909.

5. Rahman F, Kwan GF, Benjamin EJ. Global epidemiology of atrial fibrillation. Nat Rev Cardiol. 2014;11:639-54.

6. Griffin WF, Salahuddin T, O'Neal WT, Soliman EZ. Peripheral arterial disease is associated with an increased risk of atrial fibrillation in the elderly. Europace. 2016;18:794-8.

7. O'Neal WT, Efird JT, Nazarian S, Alonso A, Heckbert SR, Soliman EZ. Peripheral arterial disease and risk of atrial fibrillation and stroke: the Multi-Ethnic Study of Atherosclerosis. J Am Heart Assoc. 2014;3:e001270.

8. Chang CJ, Chen YT, Liu CS, Lin WY, Lin CL, Lin MC, Kao CH. Atrial fibrillation increases the risk of peripheral arterial disease with relative complications and mortality: a population-based cohort study. Medicine. 2016;95:e3002.

9. Wasmer K, Unrath M, Köbe J, Malyar NM, Freisinger E, Meyborg M, Breithardt G, Eckardt L, Reinecke H. Atrial fibrillation is a risk marker for worse in-hospital and long-term outcome in patients with peripheral artery disease. Int $\mathrm{J}$ Cardiol. 2015;199:223-8.

10. Kirchhof P, Benussi S, Kotecha D, Ahlsson A, Atar D, Casadei B, Castella M, Diener HC, Heidbuchel H, Hendriks J, Hindricks G, Manolis AS, Oldgren J, Popescu BA, Schotten U, Van Putte B, Vardas P, Agewall S, Camm J, Baron Esquivias G, Budts W, Carerj S, Casselman F, Coca A, De Caterina R, Deftereos S, Dobrev D, Ferro JM, Filippatos G, Fitzsimons D, Gorenek B, Guenoun M, Hohnloser SH, Kolh P, Lip GY, Manolis A, McMurray J, Ponikowski P, Rosenhek R, Ruschitzka F, Savelieva I, Sharma S, Suwalski P, Tamargo JL, Taylor CJ, Van Gelder IC, Voors AA, Windecker S, Zamorano JL, Zeppenfeld K. 2016 ESC Guidelines for the management of atrial fibrillation developed in collaboration with EACTS. Eur Heart J. 2016;37:2893-962.

11. Violi F, Daví G, Hiatt W, Lip GY, Corazza GR, Perticone F, Proietti M, Pignatelli P, Vestri AR, Basili S, ARAPACIS Study Investigators. Prevalence of peripheral artery disease by abnormal ankle-brachial index in atrial fibrillation: implications for risk and therapy. J Am Coll Cardiol. 2013;62:2255-6.

12. Dabrowski M, Lewandowski J, Abramczyk P, Lon I, Gaciong Z, Sinski M. Atrial fibrillation does not affect ankle-brachial index measured using the Doppler method. Hypertens Res. 2018;41:60-5.

13. Proietti M, Calvieri C, Malatino L, Signorelli S, Corazza GR, Perticone F, Vestri AR, Loffredo L, Davì G, Violi F, Basili S, ARAPACIS (Atrial Fibrillation Registry for Ankle-Brachial Index Prevalence Assessment-Collaborative Italian Study) STUDY Investigators. Relationship between carotid intima-media thickness and non valvular atrial fibrillation type. Atherosclerosis. $2015 ; 238: 350-5$.

14. Su HM, Lee KT, Chu CS, Lee MY, Lin TH, Voon WC, Sheu SH, Lai WT. Effects of heart rate on brachial-ankle pulse wave velocity and ankle-brachial pressure index in patients without significant organic heart disease. Angiology. 2007;58:67-74.

15. Wilkinson IB, MacCallum H, Flint L, Cockcroft JR, Newby DE, Webb DJ. The influence of heart rate on augmentation index and central arterial pressure in humans. J Physiol. 2000;525(pt 1):263-70. 